Supporting Information for:

\title{
Quantitative Molecular Characterization of Petroleum Asphaltenes Derived Ruthenium Ion Catalyzed Oxidation (RICO) Product by ESI FT-ICR MS
}

Xibin Zhou ${ }^{\dagger+}$, Suoqi Zhao ${ }^{\dagger}$, Quan $\mathrm{Shi}^{\dagger *}$

$\uparrow$ State Key Laboratory of Heavy Oil Processing, China University of Petroleum, Beijing 102249 China

${ }^{*}$ College of Basic Science, Liaoning Medical University, Jinzhou, Liaoning 121001, China

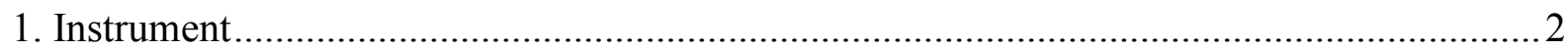

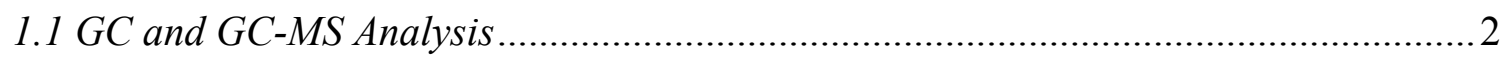

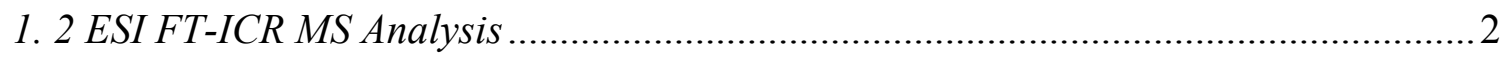

1.3 Mass Calibration and Data Analysis .............................................................. 4

2. Quantitative analysis by GC ....................................................................................

2.1 Quantification of the low mass acids in the organic and the aqueous phase (Carbon

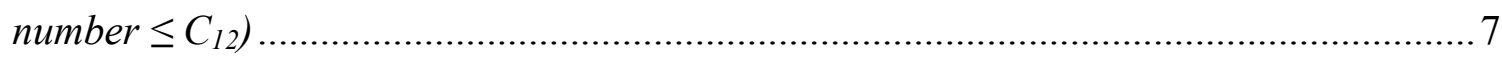

2.2 Quantification of the high mass acids in the organic phase $\left(C_{10}<\right.$ Carbon number $<$

$\left.C_{40}\right)$

2.3 Quantification of the acids in the aqueous phase....................................................... 8

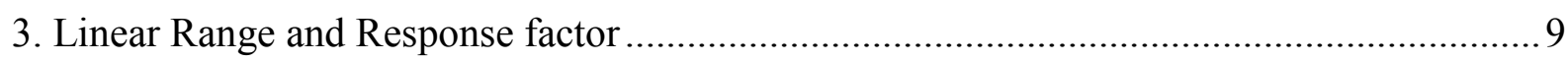

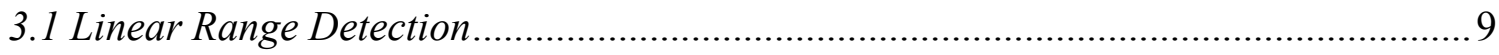

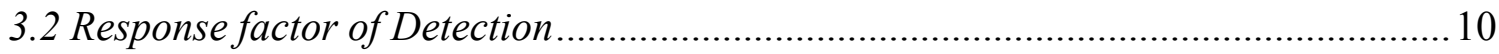

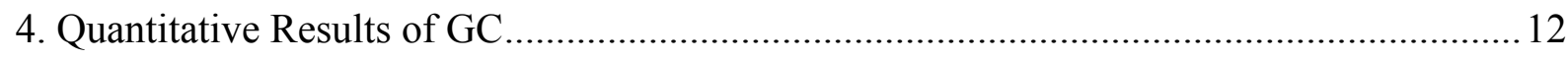

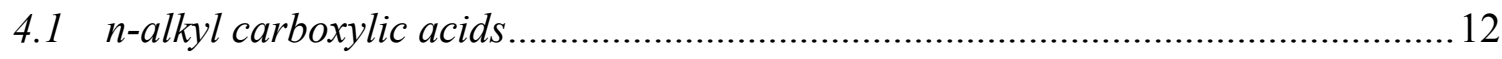

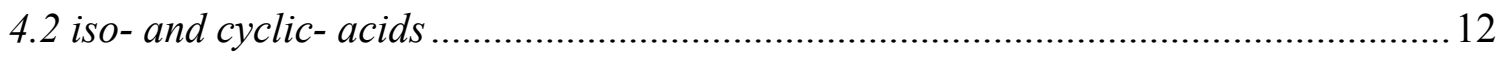

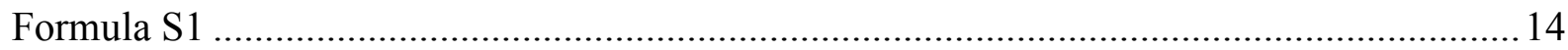

Table S1 The ESI (-) FT-ICR MS quantitative results of conditions I and II.......................... 15

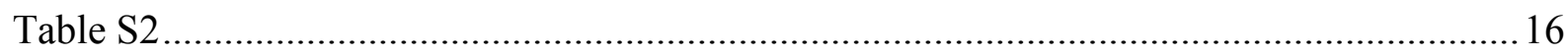

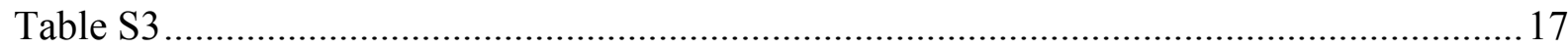




\section{Instrument}

\subsection{GC and GC-MS Analysis}

A Thermo-Finnigan Trace GC 2000 coupled with a DSQ mass detector and a Agilent GC 7890A coupled with a flame ionization detector (FID) were used to analyze the RICO products. The mass spectrometer was equipped with an EI source at $70 \mathrm{eV}$ ionization energy; the mass spectrometer was scan from $\mathrm{m} / \mathrm{z} 35$ to $\mathrm{m} / \mathrm{z} 500$ with a $1 \mathrm{~s}$ period.

A HP-FFAP $(30 \mathrm{~m} \times 0.25 \mathrm{~mm} \times 0.25 \mu \mathrm{m})$ capillary column was used for small molecule alkanoic acids (carbon number $<13$ ) analysis (both GC and GC-MS). The oven temperatures were set at $60{ }^{\circ} \mathrm{C}$ for $1 \mathrm{~min}$ and increased to $230{ }^{\circ} \mathrm{C}$ at $8{ }^{\circ} \mathrm{C} / \mathrm{min}$ and held constant at $230{ }^{\circ} \mathrm{C}$ for $20 \mathrm{~min}$. The injectors were maintained at $250{ }^{\circ} \mathrm{C}$ with splite mode.

A HP-5MS $(30 \mathrm{~m} \times 0.25 \mathrm{~mm} \times 0.25 \mu \mathrm{m})$ fused silica capillary column was used for methyl easter analysis (GC-MS). The oven temperature was set at $50{ }^{\circ} \mathrm{C}$ for 1 min and increased to $120{ }^{\circ} \mathrm{C}$ at $10{ }^{\circ} \mathrm{C} / \mathrm{min}$, then increased to $310{ }^{\circ} \mathrm{C}$ at $4{ }^{\circ} \mathrm{C} / \mathrm{min}$ and held constant at $310{ }^{\circ} \mathrm{C}$ for $35 \mathrm{~min}$. The injector was maintained at $300{ }^{\circ} \mathrm{C}$. A HP-1 $(30 \mathrm{~m} \times 0.25 \mathrm{~mm} \times 0.25$ $\mu \mathrm{m}$ ) fused silica capillary column was used for GC analysis. Oven temperature and operating conditions for $\mathrm{GC}$ analysis were same as those of GC-MS analysis.

\section{2 ESI FT-ICR MS Analysis}

Solution of toluene/methanol $(1: 3 \mathrm{vol} / \mathrm{vol})$ was use as the solvent mixture for ESI-MS. Each of the 19 model acids compounds and stearoc- $d_{35}$ acid were dissolved in the solvent and the concentration for each acid was $1 \times 10^{-2} \mathrm{~mol} / \mathrm{L}$. Then a solution containing all 19 model carboxylic acids at equal molar concentration (total acid concentration is $1.9 \times 10^{-4} \mathrm{~mol} / \mathrm{L}$ and each acid is $1.0 \times 10^{-5} \mathrm{~mol} / \mathrm{L}$ ) and solution of stearoc- $d_{35}$ acid (concentration is $1.0 \times 10^{-5} \mathrm{~mol} / \mathrm{L}$ ) were prepared. All samples were mixed and/or further diluted with the solvent (toluene $/$ methanol $=1: 3 \mathrm{vol} / \mathrm{vol}$ ) and stored in $1.5 \mathrm{~mL}$ vials with Teflon caps. For facilitate deprotonation of alcohols to yield [M-H] $]^{-}$ions, $20 \mu \mathrm{L}$ of $25 \% \mathrm{NH}_{4} \mathrm{OH}$ was added to the final solution. 
The mass spectrometry experiments were conducted on a Bruker apex-ultra 9.4 T FT-ICR MS equipped with electrospray ionization (ESI). Sample solution was introduced into the Apollo II electrospray source using a syringe pump with a $250 \mu \mathrm{L}$ syringe. The flow rate was controlled at $180 \mu \mathrm{L} / \mathrm{h}$.

The conditions-I of ESI and mass spectrometry are as follows: emitter voltage is $3.5 \mathrm{kV}$; capillary column introduce voltage is $4.0 \mathrm{kV}$; capillary exit voltage is $-320 \mathrm{~V}$; deflector plate voltage is $-300 \mathrm{~V}$; funnel 1 voltage is $-160 \mathrm{~V}$; skimmer 1 voltage is $-30 \mathrm{~V}$; funnel 2 voltage is $-6.0 \mathrm{~V}$; skimmer 2 voltage is $-5.0 \mathrm{~V}$. Source hexapole: ions accumulation time is $0.001 \mathrm{~s}$; direct current (DC) voltage is $-3.2 \mathrm{~V}$; hexapole radio-frequency (RF) amplitude is $200 \mathrm{Vpp}$; hexapole frequency is $5.0 \mathrm{MHz}$. Q1 of quadrupole is $70 \mathrm{~m} / \mathrm{z}$. An argon-filled hexapole collision pool was operated at $350 \mathrm{Vpp}$ of RF amplitude; DC extract bias voltage is $-1.1 \mathrm{~V}$; collision voltage is $1.5 \mathrm{~V}$; ions accumulation time is $0.001 \mathrm{~s}$. The extraction period for ions from the hexapole to the ICR cell is $0.0008 \mathrm{~s}$. The RF excitation of ion cyclotron resonance cell is attenuated at $15.00 \mathrm{~dB}$; the sidekick is $-20 \mathrm{~V}$; the sidekick offset is $10 \mathrm{~V}$; the front trap plate voltage is $-1.000 \mathrm{~V}$; the back trap plate voltage is $-1.050 \mathrm{~V}$; the analyzer entrance voltage is $2.0 \mathrm{~V}$. The mass range was set at $\mathrm{m} / \mathrm{z} 58$ to 1000 . The data set size is set to $256 \mathrm{~K}$. A number of 200 or 300 scan FT-ICR data sets were co-added to generate the final spectrum.

The conditions-II of ESI and mass spectrometry are as follows: emitter voltage is $4.0 \mathrm{kV}$; capillary column introduce voltage is $4.5 \mathrm{kV}$; capillary exit voltage is $-320 \mathrm{~V}$; deflector plate voltage is $-300 \mathrm{~V}$; funnel 1 voltage is $-160 \mathrm{~V}$; skimmer 1 voltage is $-30 \mathrm{~V}$; funnel 2 voltage is $-6.0 \mathrm{~V}$; skimmer 2 voltage is $-5.0 \mathrm{~V}$. Source hexapole: ions accumulation time is $0.001 \mathrm{~s}$; direct current (DC) voltage is $-3.2 \mathrm{~V}$; hexapole radio-frequency (RF) amplitude is $350 \mathrm{Vpp}$; hexapole frequency is $5.0 \mathrm{MHz}$. Q1 of quadrupole is $200 \mathrm{~m} / \mathrm{z}$. An argon-filled hexapole collision pool was operated at $1400 \mathrm{Vpp}$ of RF amplitude; DC extract bias voltage is $-1.1 \mathrm{~V}$; collision voltage is $1.5 \mathrm{~V}$; ions accumulation time is $0.001 \mathrm{~s}$. The extraction period for ions from the hexapole to the ICR cell is $0.0010 \mathrm{~s}$. The RF excitation of ion cyclotron resonance cell is attenuated at $13.00 \mathrm{~dB}$; the sidekick is $-20 \mathrm{~V}$; the sidekick offset is $4.0 \mathrm{~V}$; the front trap 
plate voltage is $-1.000 \mathrm{~V}$; the back trap plate voltage is $-1.050 \mathrm{~V}$; the analyzer entrance voltage is $2.0 \mathrm{~V}$. The mass range was set at $\mathrm{m} / \mathrm{z} 154$ to 1000 . The data set size is set to $512 \mathrm{~K}$. A number of 200 scan FT-ICR data sets were co-added to generate the final spectrum.

\subsection{Mass Calibration and Data Analysis}

Internal mass calibration was performed using acetonitrile solution of a G2421A electrospray "tuning mix" from Agilent. After analysis of the samples, the mass spectra were calibrated again using the series of $\mathrm{O}_{2}$ class species.

Data analysis was performed using the Bruker Data Analysis (DA) software. Peaks with signal/noise $(\mathrm{S} / \mathrm{N})$ greater than 5 were exported to a spreadsheet. Detailed procedure of data processing can be found in the previous publications.[1] 


\section{Figure S1}

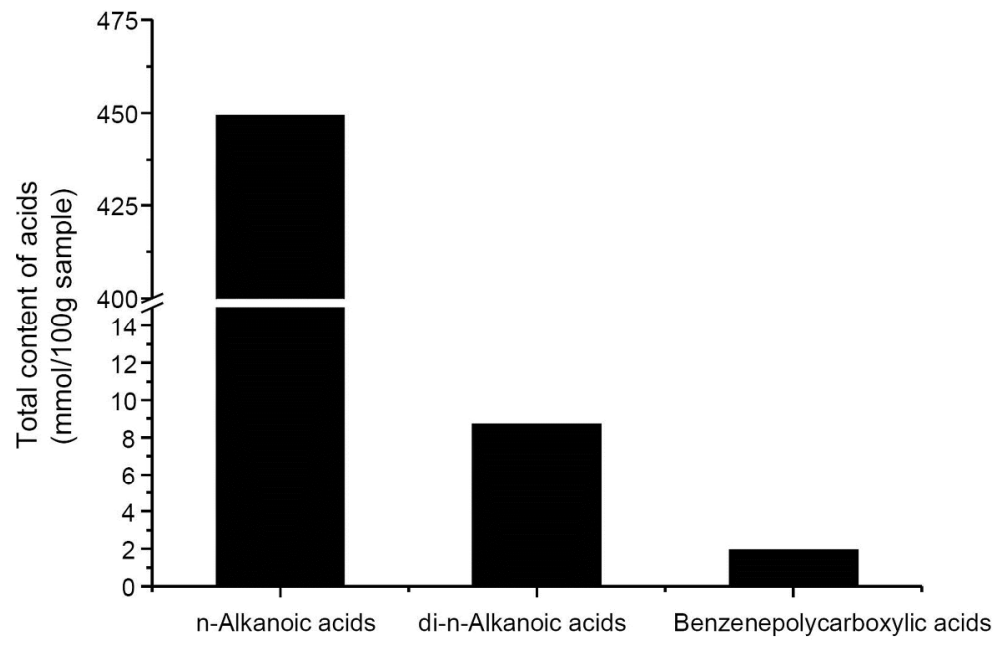

Figure S1. The total content of $n$-monocarboxylic acids, $n$-dicarbonxylic acids and benzene carboxylic acid in RICO products. 


\section{Figure S2}
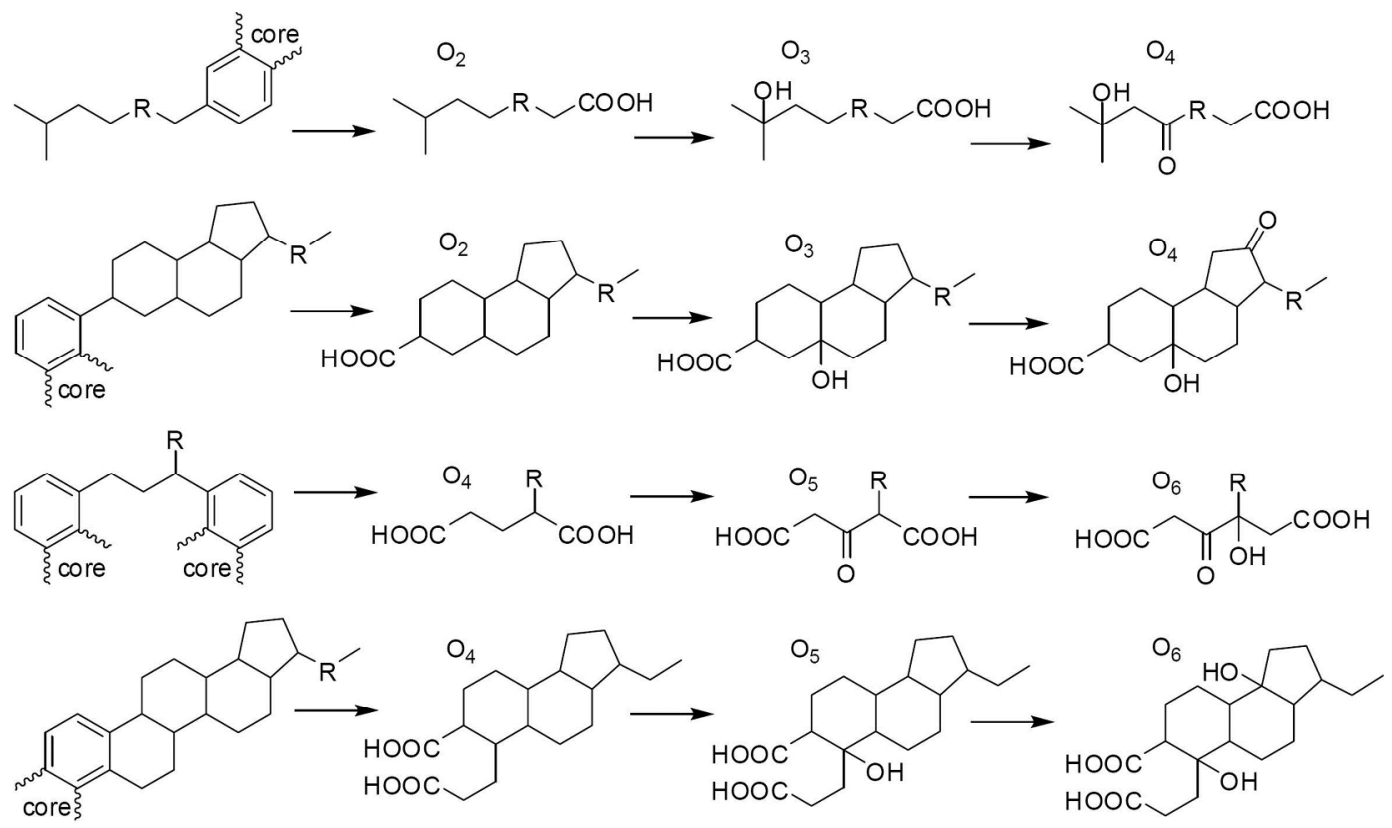

Figure S2. Possible source structures and derivative scheme for $\mathrm{O}_{n}$ class species. 


\section{Quantitative analysis by GC}

\subsection{Quantification of the low mass acids in the organic and the aqueous phase}

(Carbon number $\leq C_{12}$ )

The lower alkanoic acids in organic and aqueous phase were directly analyzed using a HP-FFAP capillary GC column of nitroterephthalic acid modified polyethylene glycol (from Agilent Ltd).

As mentioned in Experimental Section, the total volume of organic phase was determined to $100 \mathrm{~mL}$ by a volumetric flask. One milliliter organic solution was measured accurate by pipetting syringe and transferred into a $1.5 \mathrm{~mL}$ sample vials with Teflon caps (labeled 1). Then $100 \mu \mathrm{L}$ acetonitrile solution of $n$-butyric acid $(28.46 \mathrm{mg} / \mathrm{mL})$ was added to the rest of solution in volumetric flask. After evenly mixed, One milliliter organic solution was measured by pipetting syringe and transferred into another $1.5 \mathrm{~mL}$ sample vials (labeled 2).

For the quantification of the lower alkanoic acids in aqueous, the total volume of the aqueous phase was determined to $25 \mathrm{~mL}$ by a volumetric flask. $0.2 \mathrm{~mL}$ aqueous solution was measured accurate by pipetting syringe and transferred into a $1.5 \mathrm{~mL}$ sample vials with Teflon caps (labeled 3). Then $100 \mu \mathrm{L}$ acetonitrile solution of $n$-butyric acid $(28.46 \mathrm{mg} / \mathrm{mL})$ was added to the rest of solution in volumetric flask. After evenly mixed, $0.2 \mathrm{~mL}$ aqueous solution was measured by pipetting syringe and transferred into another $1.5 \mathrm{~mL}$ sample vials (labeled 4). $0.8 \mathrm{~mL}$ methanol was injected to the sample vials labeled 3 and 4 respectively to make inorganic salt liberate from the solution. After static state for 2 hour, the salt was removed by centrifugation.

The samples in vials (labeled 1, 2, 3 and 4) were subjected to GC analysis which equipped with a HP-FFAP capillary GC column. After normalized, the quantitative results of the lower alkanoic acids $\left(<\mathrm{C}_{13}\right)$ were obtained by using the increment of the $n$-butyric acid as the internal standard in the organic and the aqueous phase which after and before added the acetonitrile solution of $n$-butyric acid. GC results show that only $\mathrm{C}_{2} \sim \mathrm{C}_{5}$ alkanoic acids were found in the water phase. 
The response correction factors ( $\mathrm{RCF}$ ) for various acids relative to the $n$-butyric acid for flame ionization detector of the GC were measured to obtain more accurate quantitative results.

2.2 Quantification of the high mass acids in the organic phase $\left(C_{10}<\right.$ Carbon number $<C_{40}$ )

The carboxylic acids in the organic phases were converted to their methyl esters by diazomethane $\left(\mathrm{CH}_{2} \mathrm{~N}_{2}\right)$ and analyzed by GC-MS and GC. The solvent of the organic phase was dried in a rotary evaporator, then the acids were dissolved in THF and treated with excess diazomethane ( added by three times).

Quantification of the monocarboxylic acids use the n-docosane as internal standard. Response correction factors (RCF) for various acid methyl esters relative to the internal standard for flame ionization detector of the GC were measured to obtain accurate quantitative results.

\subsection{Quantification of the acids in the aqueous phase}

The water phase was slowly dried under lower vacuum condition at $40^{\circ} \mathrm{C}$ in a flat bottom bottle. Then $30 \mathrm{~mL}$ acetone was added to ultrasonic extract the organic acid for 20 mins. Inorganic salt was filtered by suction funnel, washed with $20 \mathrm{~mL}$ acetone. The solvent of acetone filtrate was removed by rotary evaporator, then the product was dissolved in $8 \mathrm{mLTHF}$ and underwent esterified by diazomethane. 


\section{Linear Range and Response factor}

\subsection{Linear Range Detection}

The linear range of analyte peak intensity versus concentration is important for the quantification by MS. Generally, accurate quantitative results can be obtained when the concentration of analyte within the linear range. Mass spectral peak intensity of the (stearoc- $d_{35}$ acid $\left.-\mathrm{H}\right)^{-}$ion over the range from $5 \times 10^{-8} \mathrm{M}$ to $1.9 \times 10^{-5} \mathrm{M}$ under condition I and II are plotted in Figure S3. In this concentration range, excellent linearity is observed when concentration below the $4 \times 10^{-6} \mathrm{M}$. Departure from linearity was seen when the concentration over $4 \times 10^{-6} \mathrm{M}$.

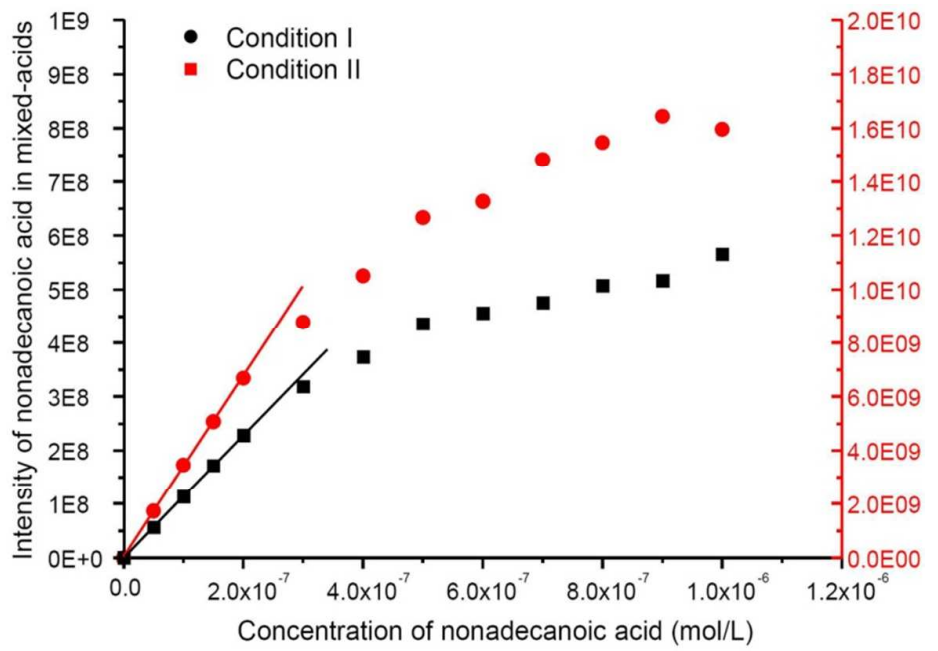

Figure S3. Plot of the monoisotopic $[\mathrm{M}-\mathrm{H}]^{-}$peak intensity for nonadecanoic acid as a function of solution concentration. The concentration of nonadecanoic acid in mixed-acid is $5 \times 10^{-8}, 1 \times 10^{-7}, 1.5 \times 10^{-7}, 2 \times 10^{-7}, 3 \times 10^{-7}, 4 \times 10^{-7}, 5 \times 10^{-7}, 6 \times 10^{-7}, 7 \times 10^{-7}, 8 \times 10^{-7}, 9 \times 10^{-7}$ and $1 \times 10^{-6}$, respectively.

Lorenz et al.[2] investigated the linear relationship between the [ratio of analyte/internal standard (IS) peak intensity] and the [ratio of analyte/IS molar concentration]. The result shown a excellent linearity over 3 orders of concentration range. We also investigated the linear relationship between the ratio of IS/analyte peak intensity and the molar concentration of $I S$. In this experiment, the stearoc- $d_{35}$ acid was used as the $I S$ and mixed model acids were used as "analyte". The peak 
intensity ratio of stearoc- $d_{35}$ 's to nonadecanoic acid under condition I and II were calculated and plotted as functions of stearoc- $d_{35}$ 's concentration. The results were shown in Figure S4. Good linear relationships between the ratio of IS/analyte peak intensity and the molar concentration of $I S$ were observed when the concentration of IS $\leq 4 \times 10^{-6} \mathrm{~mol} / \mathrm{L}$.

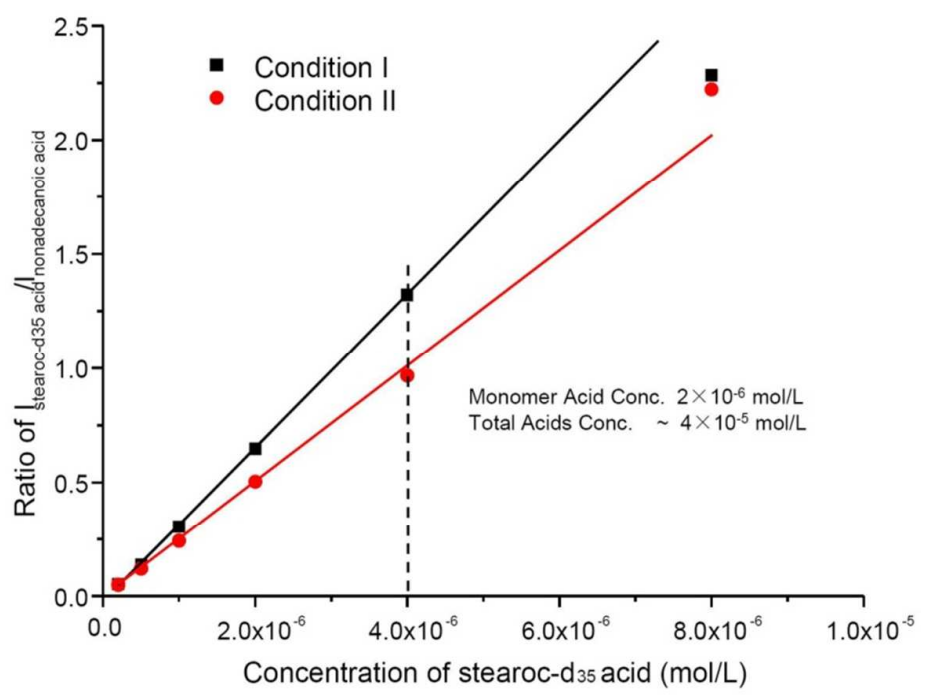

Figure S4. linear relationship between the ratio of stearoc- $d_{35}$ acid/ nonadecanoic acid peak intensity and the molar concentration of stearoc- $d_{35}$ acid in mixed-acids solution with concentration $4 \times 10^{-5} \mathrm{M}$, under condition-I and condition-II.

The results shown above indicated that the internal standard method can be readily used as the quantification method for acids sample. The next step for quantification is determine the response factors of different acids to the internal standard, just like the normal quantification processing by GC.

\subsection{Response factor of Detection}

Figure 1 shows that the response factors of acids varied obviously with carbon number and instrument condition. Generally, the response factors can be easily calculated by the peak intensity of each acid and internal standard. However, We 
found that the response factor of acid changes obviously with concentration. The response factors for 19 acids relative to the internal standard at different concentrations are different and be investigated as followed. The total concentration of acids is $2 \times 10^{-6} \mathrm{M}, 4 \times 10^{-6} \mathrm{M}, 6 \times 10^{-6} \mathrm{M}, 8 \times 10^{-6} \mathrm{M}, 1 \times 10^{-5} \mathrm{M}, 1.2 \times 10^{-5} \mathrm{M}, 1.4 \times 10^{-5}$ $\mathrm{M}, 1.6 \times 10^{-5} \mathrm{M}, 1.8 \times 10^{-5} \mathrm{M}$ respectively for each analysis (the sample include 19 model acids and stearoc- $d_{35}$ acid, the concentration of each acid for each run is equal). The results are shown in Figure S5.
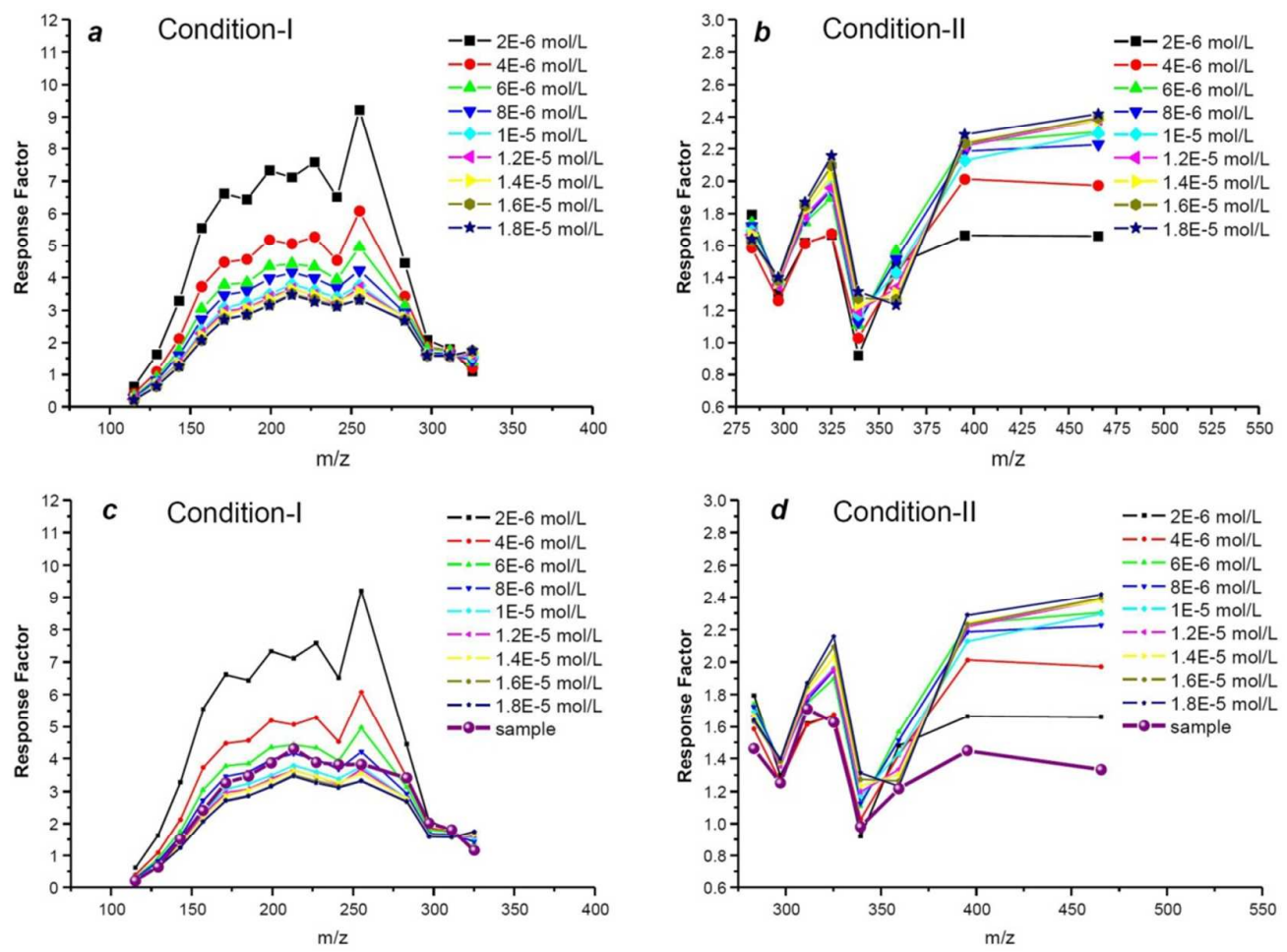

Figure S5. $a$ and $b$. The response factors of various acids relative to the stearoc- $d_{35}$ acid under different total concentrations of acids in condition I and condition II, respectively. $c$ and $d$. The position of response factor in RICO product relative to in mixed acids with different concentrations 


\section{Quantitative Results of GC}

\section{1 n-alkyl carboxylic acids}

A homologous series of $n$-alkanoic acids can be detected in the RICO product. In this paper, quantitative results of lower alkanoic acids were obtained by GC with a HP-FFAP capillary column of nitroterephthalic acid modified polyethylene glycol, and the results of higher $n$-alkanoic acids were obtained by converting them to methyl esters and subjecting to GC with a HP-1 silica capillary column. GC results shown that $\mathrm{C}_{2} \sim \mathrm{C}_{5}$ alkanoic acids were both contained in organic and water phase, and alkanoic acids with carbon number $>5$ were contained in organic phase. Figure S2a is the comparison of the quantitative results by HP-FFAP and HP-1 in the range of $7 \leq$ carbon numbers $\leq 16$. The results in the overlap area are similar to each other. The quantitative results of acids with carbon number 2-12 obtained from HP-FFAP were selected, and the results of acids with carbon number $>12$ obtained from HP-1 were selected. The combined quantitative result for $n$-alkanoic acids was shown in Figure S2b.
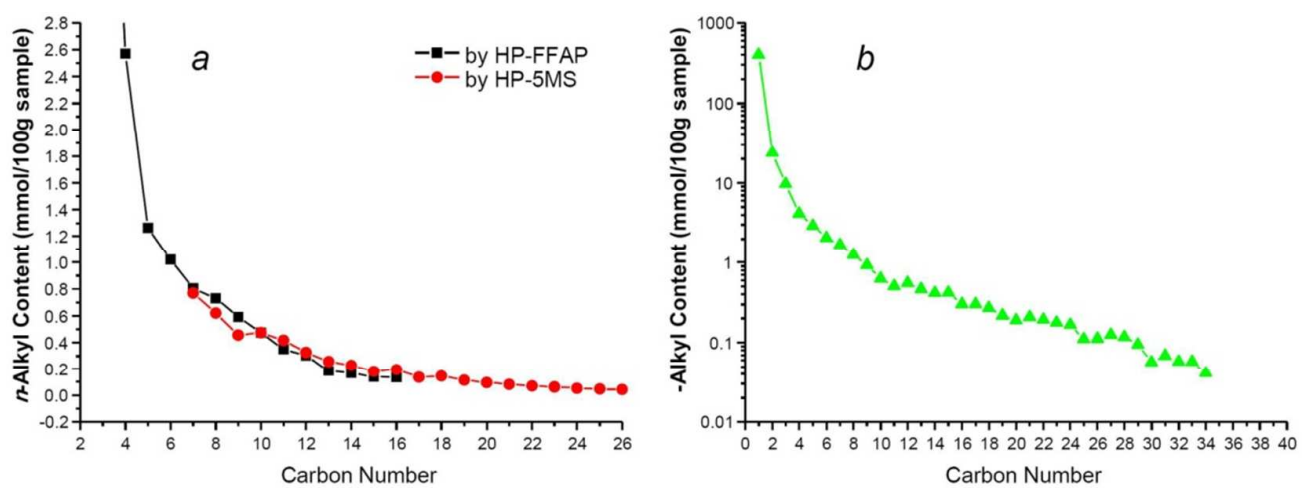

Figure S6. a. Comparison of the quantitative results by using HP-FFAP and HP-1 in the range of $7 \leq$ carbon numbers $\leq 16$; b. Quantitative distribution of $n$-alkyl groups attached to aromatic moieties in asphaltenes

\section{2 iso- and cyclic-acids}

GC results of alkanoic acids were shown in the Figure S3. Considerable peaks of 
iso- and cyclic- alkanoic acids can be observed between the peaks of $n$-alkanoic acids. The peak can be resolved when the carbon number $\leq 10$. These acids were identified by GC-MS and followed quantified by internal standard method.

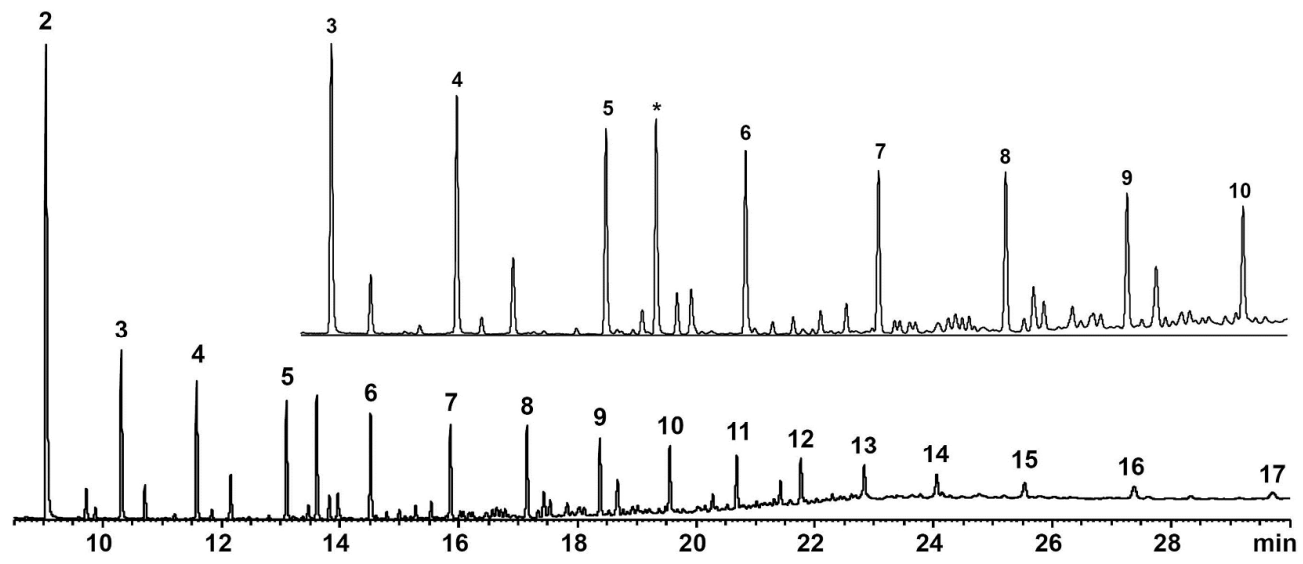

Figure S7. Gas chromatogram of lower alkanoic acids in organic phase. The minor peaks appearing in the valleys of the main series are due to iso- and naphthenic acids. Note: the peaks marked with asterisk are likely the contaminants. 


\section{Formula S1}

$$
y=y 0+\left(\frac{a}{\omega \times \sqrt{\pi / 2}}\right) e^{-2 \times((x-x c) / \omega)^{2}}+\left(\frac{a 1}{\omega 1 \times \sqrt{\pi / 2}}\right) e^{-2 \times((x-x c 1) / \omega 1)^{2}}
$$

\begin{tabular}{|l|l|l|}
\hline & Condition I & Condition II \\
\hline$y 0$ & -10.58074204755 & 0.669920008287185 \\
\hline$a$ & 51.1744869421568 & 26337737.0409825 \\
\hline$w$ & -36.4735173424373 & 2470.32517729356 \\
\hline$x c$ & 126.88600780497 & -4914.70999180053 \\
\hline$a 1$ & 5644.33444205698 & 214.730438459417 \\
\hline$w 1$ & 299.037576280627 & -85.67905949309 \\
\hline$x c 1$ & 218.929678846965 & 216.685755211609 \\
\hline
\end{tabular}


Table S1 The ESI (-) FT-ICR MS quantitative results of conditions I and II.

\begin{tabular}{|c|c|c|c|}
\hline \multirow{2}{*}{$\mathrm{NC}$} & \multirow{2}{*}{ DBE } & Condition I & Condition II \\
\hline & & $\mathrm{mmol} / 100 \mathrm{~g}$ & $\mathrm{mmol} / 100 \mathrm{~g}$ \\
\hline 15 & 1 & 0.705267 & 0.752729 \\
\hline 15 & 2 & 0.194184 & $\longrightarrow$ \\
\hline 15 & 3 & 0.060736 & $\longrightarrow$ \\
\hline 15 & 4 & 0.014699 & $\longrightarrow$ \\
\hline 15 & 5 & 0.022804 & - \\
\hline 16 & 1 & 1.085985 & 1.119402 \\
\hline 16 & 2 & 0.364314 & 0.397634 \\
\hline 16 & 3 & 0.053194 & 0.056687 \\
\hline 16 & 4 & 0.014253 & 0.015561 \\
\hline 16 & 5 & 0.005241 & 0.005968 \\
\hline 16 & 6 & $\longrightarrow$ & 0.002002 \\
\hline 17 & 1 & 0.431521 & 0.452153 \\
\hline 17 & 2 & 0.130283 & 0.151712 \\
\hline 17 & 3 & 0.059170 & 0.061138 \\
\hline 17 & 4 & 0.015052 & 0.015315 \\
\hline 17 & 5 & $\longrightarrow$ & $3.09 \mathrm{E}-03$ \\
\hline 17 & 6 & $\longrightarrow$ & $1.95 \mathrm{E}-03$ \\
\hline 18 & 1 & 0.405656 & 0.421084 \\
\hline 18 & 2 & 0.174687 & 0.180840 \\
\hline 18 & 3 & 0.058771 & 0.062940 \\
\hline 18 & 4 & 0.013281 & 0.013634 \\
\hline 18 & 5 & $\longrightarrow$ & 0.003468 \\
\hline 18 & 6 & $\longrightarrow$ & 0.001346 \\
\hline 19 & 1 & 0.242215 & 0.247826 \\
\hline 19 & 2 & 0.067170 & 0.068525 \\
\hline 19 & 3 & 0.028598 & 0.029426 \\
\hline 19 & 4 & 0.012103 & 0.011651 \\
\hline 19 & 5 & $\longrightarrow$ & 0.002812 \\
\hline 19 & 6 & $\longrightarrow$ & 0.001590 \\
\hline 20 & 1 & 0.212336 & 0.218946 \\
\hline 20 & 2 & 0.058520 & 0.060754 \\
\hline 20 & 3 & 0.029748 & 0.026972 \\
\hline 20 & 4 & 0.013425 & 0.012260 \\
\hline 20 & 5 & $\longrightarrow$ & 0.004400 \\
\hline 20 & 6 & $\longrightarrow$ & 0.001995 \\
\hline 21 & 1 & 0.228960 & 0.217305 \\
\hline 21 & 2 & 0.054142 & 0.055512 \\
\hline 21 & 3 & 0.033189 & 0.031036 \\
\hline 21 & 4 & 0.012183 & 0.011246 \\
\hline
\end{tabular}




\section{Table S2}

Number of n-alkyl groups per $100 \mathrm{~g}$ asphaltenes which calculated from ESI FT-ICR

MS and GC results.

\begin{tabular}{|c|c|c|c|c|c|c|c|}
\hline $\mathrm{mmol} / 100 \mathrm{~g}$ & DBE & & & & & & Total \\
\hline Carbon $\mathrm{N}$ & 1 & 2 & 3 & 4 & 5 & 6 & \\
\hline 2 & $3.992 \mathrm{E}+02$ & & & & & & \\
\hline 3 & $2.384 \mathrm{E}+01$ & & & & & & \\
\hline 4 & $1.127 \mathrm{E}+01$ & & & & & & \\
\hline 5 & $6.781 \mathrm{E}+00$ & & & & & & \\
\hline 6 & $5.381 \mathrm{E}+00$ & $2.415 \mathrm{E}-01$ & & & & & $4.542 \mathrm{E}+00$ \\
\hline 7 & $3.425 E+00$ & $5.668 \mathrm{E}-01$ & 3.494E-02 & & & & $4.026 \mathrm{E}+00$ \\
\hline 8 & $2.393 E+00$ & 7.033E-01 & $2.277 \mathrm{E}-02$ & & & & $3.119 \mathrm{E}+00$ \\
\hline 9 & $1.966 \mathrm{E}+00$ & 3.843E-01 & $2.714 \mathrm{E}-02$ & 7.294E-03 & & & $2.385 \mathrm{E}+00$ \\
\hline 10 & $1.756 \mathrm{E}+00$ & 4.405E-01 & $5.330 \mathrm{E}-02$ & $5.651 \mathrm{E}-03$ & $9.218 \mathrm{E}-03$ & $9.672 \mathrm{E}-3$ & $2.256 \mathrm{E}+00$ \\
\hline 11 & $1.374 \mathrm{E}+00$ & $3.608 \mathrm{E}-01$ & $6.496 \mathrm{E}-02$ & $5.373 \mathrm{E}-03$ & $2.628 \mathrm{E}-02$ & $1.049 \mathrm{E}-2$ & $1.805 \mathrm{E}+00$ \\
\hline 12 & $1.091 \mathrm{E}+00$ & 2.879E-01 & 7.204E-02 & 7.561E-03 & 4.476E-03 & $7.426 \mathrm{E}-3$ & $1.463 \mathrm{E}+00$ \\
\hline 13 & $9.183 E-01$ & 2.213E-01 & 7.625E-02 & $9.708 \mathrm{E}-03$ & 3.696E-03 & 4.892E-3 & $1.229 \mathrm{E}+00$ \\
\hline 14 & $8.549 \mathrm{E}-01$ & $2.305 \mathrm{E}-01$ & 7.034E-02 & $1.915 \mathrm{E}-02$ & $2.845 \mathrm{E}-03$ & $3.088 \mathrm{E}-3$ & $1.178 \mathrm{E}+00$ \\
\hline 15 & 7.053E-01 & 1.942E-01 & $6.074 \mathrm{E}-02$ & $1.470 \mathrm{E}-02$ & $2.280 \mathrm{E}-02$ & & 9.977E-01 \\
\hline 16 & $1.119 \mathrm{E}+00$ & 3.976E-01 & $5.669 \mathrm{E}-02$ & 1.556E-02 & $5.968 \mathrm{E}-03$ & 2.002E-03 & $1.597 \mathrm{E}+00$ \\
\hline 17 & 4.522E-01 & $1.517 \mathrm{E}-01$ & 6.114E-02 & 1.532E-02 & 3.087E-03 & 1.953E-03 & $6.854 \mathrm{E}-01$ \\
\hline 18 & 4.211E-01 & 1.808E-01 & $6.294 \mathrm{E}-02$ & 1.363E-02 & $3.468 \mathrm{E}-03$ & 1.346E-03 & 6.833E-01 \\
\hline 19 & $2.478 \mathrm{E}-01$ & 6.852E-02 & 2.943E-02 & 1.165E-02 & 2.812E-03 & $1.590 \mathrm{E}-03$ & $3.618 \mathrm{E}-01$ \\
\hline 20 & 2.189E-01 & 6.075E-02 & 2.697E-02 & $1.226 \mathrm{E}-02$ & 4.400E-03 & $1.995 \mathrm{E}-03$ & 3.253E-01 \\
\hline 21 & 2.173E-01 & $5.551 \mathrm{E}-02$ & 3.104E-02 & 1.125E-02 & 3.546E-03 & $1.070 \mathrm{E}-03$ & 3.197E-01 \\
\hline 22 & $1.754 \mathrm{E}-01$ & 5.094E-02 & 2.642E-02 & $1.264 \mathrm{E}-02$ & 6.306E-03 & 1.096E-03 & $2.728 \mathrm{E}-01$ \\
\hline 23 & $1.425 \mathrm{E}-01$ & 4.120E-02 & $2.746 \mathrm{E}-02$ & $9.233 \mathrm{E}-03$ & $6.530 \mathrm{E}-03$ & $1.038 \mathrm{E}-03$ & $2.280 \mathrm{E}-01$ \\
\hline 24 & $1.222 \mathrm{E}-01$ & $3.516 \mathrm{E}-02$ & $1.827 \mathrm{E}-02$ & $1.095 \mathrm{E}-02$ & $1.258 \mathrm{E}-02$ & $1.345 \mathrm{E}-03$ & $2.005 \mathrm{E}-01$ \\
\hline 25 & 1.103E-01 & 3.265E-02 & $1.444 \mathrm{E}-02$ & 1.100E-02 & 4.894E-03 & $1.118 \mathrm{E}-03$ & $1.744 \mathrm{E}-01$ \\
\hline 26 & $9.580 \mathrm{E}-02$ & 2.722E-02 & $1.241 \mathrm{E}-02$ & 8.346E-03 & $4.828 \mathrm{E}-03$ & 1.193E-03 & $1.498 \mathrm{E}-01$ \\
\hline 27 & 6.966E-02 & 2.306E-02 & 1.113E-02 & $6.705 \mathrm{E}-03$ & 4.896E-03 & $1.586 \mathrm{E}-03$ & 1.170E-01 \\
\hline 28 & $6.508 \mathrm{E}-02$ & 2.162E-02 & 1.102E-02 & $6.225 \mathrm{E}-03$ & $9.253 \mathrm{E}-03$ & $3.692 \mathrm{E}-03$ & 1.169E-01 \\
\hline 29 & $4.686 \mathrm{E}-02$ & 1.713E-02 & 8.362E-03 & $5.576 \mathrm{E}-03$ & $9.158 \mathrm{E}-03$ & $2.416 \mathrm{E}-03$ & $8.950 \mathrm{E}-02$ \\
\hline 30 & 4.326E-02 & $1.523 \mathrm{E}-02$ & 7.661E-03 & $5.450 \mathrm{E}-03$ & 1.203E-02 & $5.418 \mathrm{E}-03$ & $8.905 \mathrm{E}-02$ \\
\hline 31 & 4.346E-02 & $1.402 \mathrm{E}-02$ & 7.203E-03 & 4.348E-03 & 8.463E-03 & $9.441 \mathrm{E}-03$ & 8.694E-02 \\
\hline 32 & 3.073E-02 & 1.191E-02 & 6.639E-03 & 4.073E-03 & 5.341E-03 & $1.090 \mathrm{E}-02$ & $6.959 \mathrm{E}-02$ \\
\hline 33 & $2.569 \mathrm{E}-02$ & 1.102E-02 & $5.534 \mathrm{E}-03$ & 3.597E-03 & $3.838 \mathrm{E}-03$ & 7.604E-03 & $5.728 \mathrm{E}-02$ \\
\hline 34 & $2.293 \mathrm{E}-02$ & $9.797 \mathrm{E}-03$ & $5.415 \mathrm{E}-03$ & $3.504 \mathrm{E}-03$ & 3.206E-03 & 4.636E-03 & 4.949E-02 \\
\hline 35 & 2.062E-02 & 8.967E-03 & 5.195E-03 & 3.659E-03 & 2.704E-03 & $3.684 \mathrm{E}-03$ & 4.483E-02 \\
\hline 36 & $1.627 \mathrm{E}-02$ & 7.879E-03 & 4.347E-03 & 3.674E-03 & 2.304E-03 & 3.304E-03 & $3.778 \mathrm{E}-02$ \\
\hline 37 & 1.173E-02 & $5.781 \mathrm{E}-03$ & $3.499 \mathrm{E}-03$ & $2.408 \mathrm{E}-03$ & 1.692E-03 & & $2.511 \mathrm{E}-02$ \\
\hline 38 & 1.032E-02 & $5.280 \mathrm{E}-03$ & $3.240 \mathrm{E}-03$ & $1.664 \mathrm{E}-03$ & 1.316E-03 & & 2.181E-02 \\
\hline 39 & $8.308 \mathrm{E}-03$ & 4.623E-03 & $2.625 \mathrm{E}-03$ & $1.932 \mathrm{E}-03$ & $1.685 \mathrm{E}-03$ & & $1.917 \mathrm{E}-02$ \\
\hline 40 & $6.141 \mathrm{E}-03$ & 3.184E-03 & 2.313E-03 & $1.730 \mathrm{E}-03$ & & & 1.337E-02 \\
\hline 41 & $5.000 \mathrm{E}-03$ & 3.212E-03 & 2.131E-03 & $1.554 \mathrm{E}-03$ & & & 1.190E-02 \\
\hline 42 & $3.826 \mathrm{E}-03$ & $1.941 \mathrm{E}-03$ & $1.576 \mathrm{E}-03$ & $1.014 \mathrm{E}-03$ & & & 8.356E-03 \\
\hline 43 & $2.047 \mathrm{E}-03$ & & & & & & 2.047E-03 \\
\hline Total & $4.647 \mathrm{E}+02$ & $4.898 \mathrm{E}+00$ & 9.376E-01 & $2.584 \mathrm{E}-01$ & $1.581 \mathrm{E}-01$ & 6.843E-02 & $4.710 \mathrm{E}+02$ \\
\hline
\end{tabular}




\section{Table S3}

Table S3. Carbon recovery

\begin{tabular}{|c|c|c|c|c|c|}
\hline Object & $\begin{array}{c}\text { Monoaci } \\
\text { d }\end{array}$ & $\begin{array}{c}\text { di- } n \text {-Alkanoic } \\
\text { acid }\end{array}$ & $\begin{array}{c}\text { Aromatic } \\
\text { acid }\end{array}$ & $\mathrm{CO}_{2}$ & Total Carbon \\
\hline Method & $\mathrm{ESI}+\mathrm{GC}$ & $\mathrm{GC}$ & $\mathrm{GC}$ & Absorption & \\
\hline Percentage & $20.1 \%$ & $0.8 \%$ & $0.3 \%$ & $21.5 \%$ & $42.7 \%$ \\
\hline
\end{tabular}

The equivalent carbon percent in the asphaltene for monoacid, di- $n$-alkanoic acid, benzene carboxylic acids, $\mathrm{CO}_{2}$ and the total carbon recovery were calculated and shown in Table S3. The quantified monoacids afford $20.1 \%$ carbon recovery. The carbon recovery of alkyl group calculated from the monoacids is $12.4 \%$ (the carbon on carboxyl group should be classified to aromatic carbon), while the percent aliphaticity of Canada oil sand asphaltene by Hazendonk is about 50\% (calculated by solid ${ }^{13} \mathrm{C}$ NMR).[3] The average aliphatic chain length calculated from the quantitative results of monoacids is 1.73 , which far lower than the value 4 in reference.[3] The $42.7 \%$ total carbon recovery also indicated that present obtained quantitative result is one piece of a jigsaw. Other unrecovered portion include the di-iso-alkanoic acid, diacid naphthenic derivatives, the further oxidation product of $\mathrm{O}_{2}$ and $\mathrm{O}_{4}$ species, $\mathrm{SO}_{x}$ and $\mathrm{NO}_{y}$ compounds. Qualitative results for this portion have shown in Figure 5-8, but quantitative analyze need a further study on RICO reactions or assist by other new method or techniques. 
1. Shi, Q., Pan, N., Long, H., Cui, D., Guo, X., Long, Y., Chung, K. H., Zhao, S., Xu, C., and Hsu, C. S., Characterization of Middle-Temperature Gasification Coal Tar. Part 3: Molecular Composition of Acidic Compounds. Energy \& Fuels, 2013. 27(1): 108-117.

2. Lorenz, S. A., Moy, M. A., Dolan, A. R., and Wood, T. D., Electrospray Ionization Fourier Transform Mass Spectrometry Quantification of Enkephalin Using an Internal Standard. Rapid Communications in Mass Spectrometry, 1999. 13(21): 2098-2102.

3. Dutta Majumdar, R., Gerken, M., and Hazendonk, P., Solid-State $1 \mathrm{~h}$ and 13c Nuclear Magnetic Resonance Spectroscopy of Athabasca Oil Sands Asphaltenes: Evidence for Interlocking П-Stacked Nanoaggregates with Intercalated Alkyl Side Chains. Energy \& Fuels, 2015. 29(5): 2790-2800. 